\title{
Intentional injury patientsattending a Nigerian Accident and Emergency Department
}

\author{
Itodo C. Elachi, Williams T. Yongu, Ndubuisi OC. Onyemaechi ${ }^{1}$, \\ Daniel D. Mue, Livinus Egwuda ${ }^{2}$ \\ Department of Surgery, Benue State University, Makurdi, Nigeria \\ ${ }^{I}$ Department of Surgery, University of Nigeria Teaching Hospital, Ituku-Ozalla, Enugu, Nigeria \\ ${ }^{2}$ Department of Family Medicine, Benue State University Teaching Hospital, Makurdi, Nigeria
}

\begin{abstract}
Intentional injuries are a common presentation to Accident and Emergency (A\&E) Departments and make a significant contribution to the global injury burden. This descriptive study aims to determine the pattern and treatment outcome of intentional injuries presenting to the A\&E Department of Benue State University Teaching Hospital, Makurdi, Nigeria (BSUTH). Case records of all patients who presented to the A\&E Department between July 2012 and December 2013 were analyzed for age, gender, circumstance surrounding injury, weapon used, body region injured, injury sustained, treatment offered, and outcome of treatment. Sixty patients with intentional injuries were included in the study. They consisted of 50 males (83.3\%) and 10 females (16.7\%) with ages ranging from 15 to 65 years with a modal age group of 20-29 years. The extremities were the most predominantly injured body regions $(n=26,43.3 \%)$ and firearms were the most common weapons employed $(n=31,51.7 \%)$. While armed robbery $(n=31,51.7 \%)$ was the most common reason for the injuries, attempted suicide $(n=2,3.3 \%)$ was the least. Soft tissue injuries and debridement were the most common injury type and treatment modality encountered respectively.The death rate was $8.3 \%$ with majority of deaths (80\%) resulting from firearm injuries.
\end{abstract}

Keywords: Intentional injury, violence, Accident and Emergency, Nigeria

\section{Introduction}

Intentional or violent injuries result from self-directed, interpersonal and collective violence. Violence has probably always been part of the human experience and is important to study across the life span, from child maltreatment to elder abuse. ${ }^{1,2}$ Intentional injuries are a common presentation toAccident and Emergency Departmentsand make a significant contribution to the global burden of disease.

Intentional injuries present a threat to the physical and psychological wellbeing of victims and are associated with substantial emotional and financial burden on community and hospital resources. ${ }^{3}$ In 2000 , an estimated 1.6 million people worldwide died as a result of self-inflicted, interpersonal or collective violence, for an overall age-adjusted rate of 28.8 per 100000 population. ${ }^{4}$ Violent injuries are among the top three causes of death for persons between the ages of 10 to 34 years and rank in the top 10 causes of death for persons between the ages of 1 and 64 years. ${ }^{5}$

Mortality figures are an underestimate of the true burden of intentional injuries. Not all assaults result in injuries severe enough to require medical attention and - even among those that do result in serious injuries surveillance systems for reporting and compiling these injuries are in many countries either lacking or are still being developed. ${ }^{4}$ Intentional injuries exact a hugeeconomic toll on the society. Their emergency treatment, hospitalization and long term care divert scarce resources from other development priorities. ${ }^{2}$ The direct and indirect annual costs of gunshot, cutting or stab wounds in the United States were estimated to be US\$ 177 billion. $^{6}$

The vast majority of deaths from violence occurred in low- to middle-income countries ${ }^{4}$ There is paucity of information in most developing countries on both morbidity and mortality due to intentional injuries where greater emphasis has been placed on injuries related to road traffic crashes, which are more common. ${ }^{2}$ Prevention of violent injuries involves addressing circumstances that result in violence, prompt treatment of injuries sustained and rehabilitation of disabled victims. A comprehensive preventive program can only be formulated when there is adequate data on magnitude and impact of the injuries. This study aims to determine the injury pattern and treatment outcome of intentional injuries presenting to the A\&E Department.

\section{Study design and setting}

\section{Patients and methods}

This was a hospital-based study of patients who presented with intentional injuries to theA\&EDepartment of BSUTH from July 2012 to December 2013. BSUTH is a tertiary care and teaching 
hospital for the Benue State University and is located along the shores of River Benue. There is no major trauma center in the city as such most seriously injured patients are referred to the facility. It provides care for inhabitants of the city and surrounding areas of north central Nigeria.

\section{Study population}

The case records of all patients seen with intentional injuries at the A\&E Department during the study period were retrieved. Demographic data, types of injuries sustained, causes and circumstances of injuries as well as outcome of treatment were extracted from the case files and entered into a computerized questionnaire.

\section{Statistical analysis}

Data were analyzed using the software IBM SPSS Statistics for Windows, Version 21.0. Armonk, NY: IBM Corp. Descriptive statistics were used to display single variable quantities using means and standard deviations (SD) for continuous variables or proportions for categorical variables unless otherwise stated.

\section{Results}

Five hundred and ninety four trauma patients were seen at the A\&E department during the study period of whom $60(10.1 \%)$ sustained intentional injuries and were included in the study. Males were $50(83.3 \%)$ and females $10(16.7 \%)$ with a male-female ratio of $5: 1$. Their ages ranged from 15 to 65 with a modal age group of 20-29 years.[Figure 1]The extremities (mainly the upper limbs) and head were the most predominantly injured body regions involved in $(n=26,43.3 \%)$ and $(n=20,33.3 \%)$ respectively.[Table 1]The most common weapons used were firearms $(n=31,51.7 \%)$,sharp penetrating objects $(n=11,18.3 \%)$, machete $(n=8,13.3 \%)$, blunt objects $(n=7,11.7 \%)$, Fists/Slap/Kicks $(n=2,3.3 \%)$ and chemicals $(n=1,1.7 \%)$.Reasons for intentional injuries were armed robbery $(\mathrm{n}=31,51.7 \%)$, assault $(\mathrm{n}=14,23.3 \%)$ and attempted suicide $(\mathrm{n}=2,3.3 \%)$. Domestic violence accounted for $5 \%$ of all injuries withall assailants being spouses. [Table 2] Most patients (96.7\%) claimed to be victims. Soft tissue injuries (bruises, abrasions and lacerations) were the most common injury type affecting $(\mathrm{n}=17,28 \%)$ of cases. Among head injured patients, $64.3 \%$ patients had mild head injuries (Glasgow coma score $(\mathrm{GCS})=13-15), 21.4 \%$ had moderate head injuries $(\mathrm{GCS}=9-12)$ and $14.3 \%$ severe head injuries $(\mathrm{GCS}=3-8)$.Majority $(\mathrm{n}=57,95 \%)$ of patients were treated surgically and the rest, by non-operative approach. Wound debridement for soft tissue injuries was the most predominant surgical procedure carried out. [Figure 2] A total of four patients died of their injuries while on admission giving a death rate of $8.3 \%$.

Figure 1: Age distribution of intentional injury patients

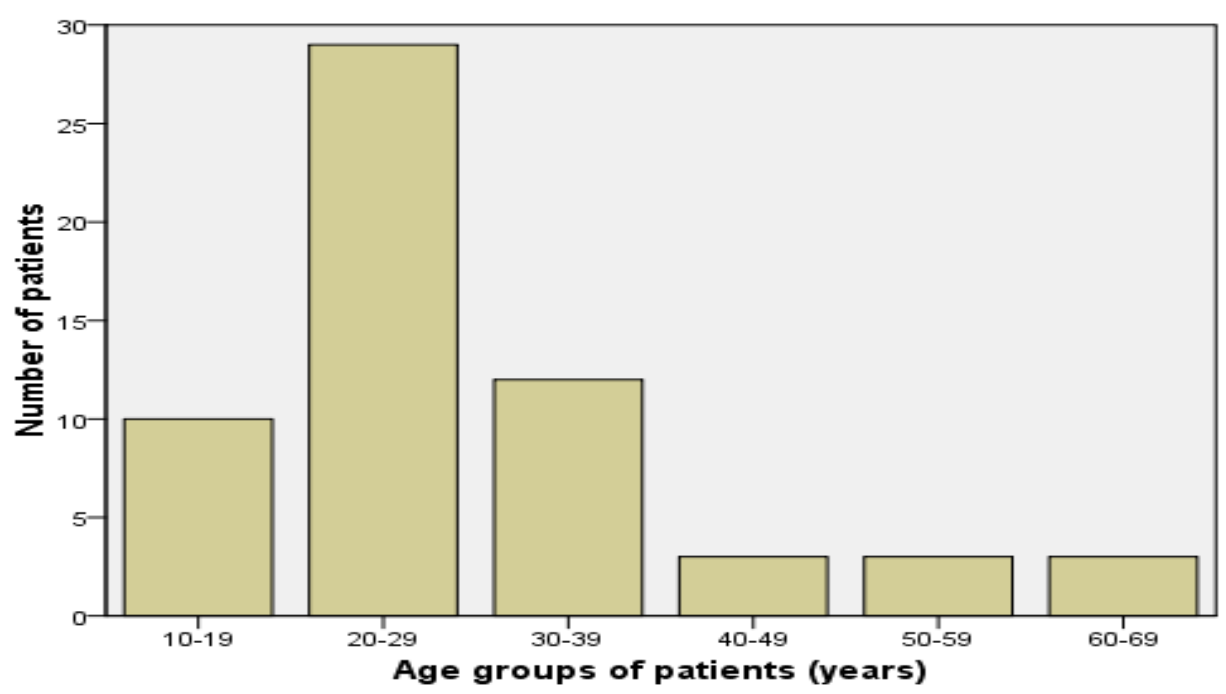

Table 1: Sites of injuries among victims

\begin{tabular}{lcc}
\hline Body Region & Frequency & Percent \\
\hline Upper Limbs & 14 & 23.3 \\
Lower Limbs & 12 & 20.0 \\
Chest & 7 & 11.7 \\
Abdomen & 5 & 8.3 \\
Spine & 2 & 3.3 \\
Head & 20 & 33.3 \\
\hline Total & $\mathbf{6 0}$ & $\mathbf{1 0 0 . 0}$ \\
\hline
\end{tabular}


Table 2: Reasons for intentional injuries with relation to sex distribution

\begin{tabular}{llll}
\hline Reason & Male & Female & Total \\
\hline Armed robbery & 18 & 2 & 20 \\
Assault & 13 & 1 & 14 \\
Cult violence & 9 & 2 & 11 \\
Communal clash & 5 & 2 & 7 \\
Domestic violence & 1 & 2 & 3 \\
Policemen & 2 & 1 & 3 \\
Attempted suicide & 1 & 1 & 2 \\
\hline Total & $\mathbf{5 0}$ & $\mathbf{1 0}$ & $\mathbf{6 0}$ \\
\hline
\end{tabular}

Figure 2: Treatment modalities offered to victims of intentional injuries

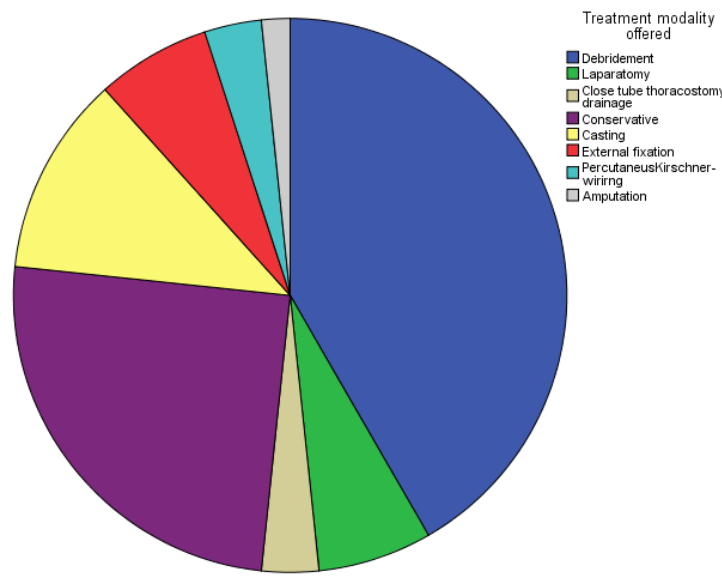

IV. Discussion

This observational study shows intentional injuries constituted $10.1 \%$ of all trauma cases that presented to the A\&E Department. The figure is lower than that reported in a similar study from Tanzania. ${ }^{3}$ The relatively lower proportion in this study may be due to differences in risk factors for intentional injuries among different settings. The true magnitude of the burden of intentional injuries in Makurdi may be difficult to capture in this study as only non-fatal injuries and in-hospital mortalities were studied. The fact that a number of injured patients may not even report to the hospital at all further complicates the issue. A truer reflection of the picture may be obtained from more encompassing studies involving population-based studies, police records, mortuary and in-patient data.

The brunt of intentional injuries is borne by young adult males in the productive period of their lives in consonance with other studies. ${ }^{3,7,8}$ Young adult males are more likely to be involved in civil conflicts, armed banditry, and brawls. Loss of this economically active segment of the society reduces the productivity of the nation. Engaging the youth in productive endeavors may help keep them off the path of violence which may save a lot in terms of lost man-hours, human grief and costs of treatment and rehabilitation.

Firearms were the most predominant agent of injury, a finding similar to that of a study from Pakistan. ${ }^{7}$ This is in contrast, though, to studies that revealed blunt/sharp objects ${ }^{3}$ and fists, slaps and kicks. ${ }^{9}$ Firearm injuries are a unique form of trauma that may require expertise to tackle. Tissue damage in high velocity injuries occur remote from the tract of missiles. The paths of wounding missiles are difficult to predict as a missile propagated on to the abdomen may end in the chest requiring experience in treating both abdominal and chest injuries. Firearm injuriesthat were a rarity in Nigeria before her civil war became prevalent following an influx of arms from conflicts around neighboring countries. ${ }^{10}$ Strict enforcement of arms-control may go a long way in stemming this tide.

Armed robbery made the highest contribution to the burden of intentional injuries in this study. High rate of unemployment, unfavorable economic conditions and poor law enforcement in the country are some reasons that may be responsible for armed banditry. While domestic violence was the leading cause of intentional injuries in a similar study ${ }^{9}$ its contribution in this study was modest. This may be a result of underreporting due to sociocultural attitude of maintaining family honor. While most studies report physical injuries in domestic violence, not much is said about the psychological aspects of such abuse. All the perpetrators in this study were intimate partners.

An understanding of the body region injured while inflicting intentional injuries could give a guide as to the intent of the attacker in medico-legal jurisprudence. The finding in this study that the extremities and head were the most frequently injured body regions is supported by a similar study in Tanzania. ${ }^{3}$ The upper 
extremities were particularly more predisposed to intentional injuries possibly because they were employed in defensive modes during incidents. Aiming for the head may indicate a desire to kill the victim.

The study had a death rate of $8.3 \%$ which was higher than that reported in a similar study. ${ }^{9}$ Most of the deaths $(80 \%)$ were as a result of firearm injuries. This is not surprising as firearms were the most common weapons used to inflict intentional injuries in this study. The higher mortality associated with firearm injuries may be because of the indiscriminate tissue wounding which results from high velocity missiles. Efforts to curb widespread availability of firearms may help improve outcome from these injuries.

\section{Conclusion}

Intentional injuries predominantly affect adult young males in Makurdi. They are mostly inflicted with firearms during armed robbery incidents. The extremities were the body region most injured. The majority of patients sustained soft tissue injuries and a death rate of $8.3 \%$ was recorded.

\section{Acknowledgement}

We wish to thank the staff of Records Department, BSUTH, for retrieving case notes and I F Elachi for secretarial work.

\section{References}

[1]. Krug EG et al., eds. World report on violence and health. Geneva: World Health Organization: 2002.

[2]. Houry D, Cunningham RM, Hankin A, James T, Bernstein E, and Hargarten S. Violence Prevention in the Emergency Department: Future Research Priorities Academic Emergency Medicine 2009;16:1089-95.

[3]. Chalya PL, Gilyoma JM. The burden of intentional injuries in Mwanza City, north-western Tanzania: a tertiary hospital survey. Tanzania Journal of Health Research 2012;14(3): 1-10.

[4]. Murray CJL, Lopez AD, Mathers CD, Stein C. The Global Burden of Disease 2000project: aims, methods and data sources.Geneva, WHO 2001.

[5]. Centers for Disease Control and Prevention, National Center for Injury Prevention and Control. Web-based Injury Statistics Query and Reporting System (WISQARS). Available at: http://www.cdc.gov/injury/wisqars/index.html. Accessed 1 November 2014

[6]. Miller TR, Cohen MA. Costs of gunshot and cut/stab wounds in the United States, with some Canadian comparisons. Accident Analysis and Prevention 1997;29:329-341.

[7]. Chotani HA, Razzak JA, Luby SP. Patterns of violence in Karachi, Pakistan. InjPrev2002;8:57-9

[8]. Lule, E., Rosen, J.E., Singh, S., Knowles, J.C. \& Behrman, J.R Adolescent health programs. In Disease Control Priorities in Developing Countries. 2nd edition. NewYork: Oxford University Press; 2006.p1109-26.

[9]. Mugala DD, Imataa D. Admissions for Physical Violence in Chingola -Zambia. East and Central African Journal of Surgery 2007; 12: $68-73$.

[10]. Udosen AM, Eliuma AU, Ugare GA, Bassey OO. (2006) Gunshot injuries in Calabar, Nigeria: an indication of increasing societal violence and police brutality. African Health Science 2006;6: 170-172. 